\title{
Knowledge, attitudes, and beliefs of healthcare workers regarding stem cell research
}

\author{
Deng Luo ${ }^{1}$, Wenzhuo Ran ${ }^{2 *}$, Gongfang Zhao ${ }^{3}$, Chaxiang Guan ${ }^{2}$, Chen Wang ${ }^{1 *}$ \\ \& Weiping $\mathrm{Jia}^{1}$ \\ ${ }^{1}$ Department of Endocrinology and Metabolism, Shanghai Jiao Tong University Affiliated Sixth People's Hospital; Shanghai Key Laboratory \\ of Diabetes Mellitus, Diabetes Institute, Shanghai 200233, China; \\ ${ }^{2}$ Department of Physiology, Xiangya School of Medicine, Central South University, Changsha 410078, China; \\ ${ }^{3}$ Department of Gastroenterology, The Second Affiliated Hospital of Kunming Medical University, Kunming 650101, China
}

Received March 27, 2015; accepted April 16, 2015; published online June 19, 2015

Citation: Luo, D., Ran, W., Zhao, G., Guan, C., Wang, C., and Jia, W. (2016) Knowledge, attitudes, and beliefs of healthcare workers regarding stem cell research. Sci China Life Sci 59, 325-327, doi: 10.1007/s11427-015-4884-6

\section{Dear Editors,}

China has made rapid advances in the field of stem cell research, especially in terms of the scale of financing received, numbers of published papers, and investors and new investment products (Yuan et al., 2012). Accordingly, public knowledge on stem cell research has also increased dramatically. Despite their widespread implementation, specific assessment of Chinese medical workers' attitudes toward such research is lacking. In order to evaluate and analyze their knowledge and information level about the scientific and therapeutic potential of stem cells, and to verify their attitudes toward different types of stem cells, the nationwide survey study was conducted between December 2013 and August 2014. A questionnaire was distributed to the randomly selected healthcare workers from 32 university hospitals, from 25 cities (e.g., Beijing, Shanghai, Guangzhou, Wuhan, Changsha, and Chengdu) representing China's different geographical regions: South $(6.1 \%)$, East $(24.03 \%)$, North (13.98\%), Northeast (11.17\%), Central (30.78\%), Southwest (9.18\%), and Northwest (4.76\%). Survey responses were anonymous, and 2,310 responses were received.

As shown in Figure 1A, the mean age of the participants

*Corresponding author (email: y.dwz@163.com; wangchenstju@ 163.com)) was $24.8 \pm 4.0$ years. Among all of healthcare workers who participated in this survey, $1,183(51 \%)$ were men, and $1,116(48 \%)$ were women. Most of the participants had a bachelor's degree or higher: doctoral degree (12.3\%), master's degree $(48.1 \%)$, and bachelor's degree (39.5\%). In this survey, we found that the levels of factual knowledge about stem cell science appeared to be high among our medical workers. About $99.1 \%$ of them had heard of stem cell research, and said that the Internet and newspapers were the most common ways to acquire knowledge on stem cell research. While people acquired the knowledge on stem cells via multiple sources, deriving such knowledge from newspapers tended to be more common in China. Approximately 2,016 news reports were published by Chinese newspapers between 2000 and 2014 (Figure 1B). The growth of publications was relatively rapid from 2000 to 2006, but the number started to tail off after 2006. These statistics might reflect great effort by China to support stem cell and regenerative medicine, and would strengthen the role of China's science and technology in the stem cell community. Of all newspaper publishers, the Science and Technology Daily topped the list in terms of number of articles on stem cells (Figure 1C), followed by the China Pharmaceutical News, Medicine Economic News, Health News, and Xinhua Daily Telegraph.

In addition, we found that knowledge of stem cells varied significantly by type, where $87.3 \%$ of the participants were 
A

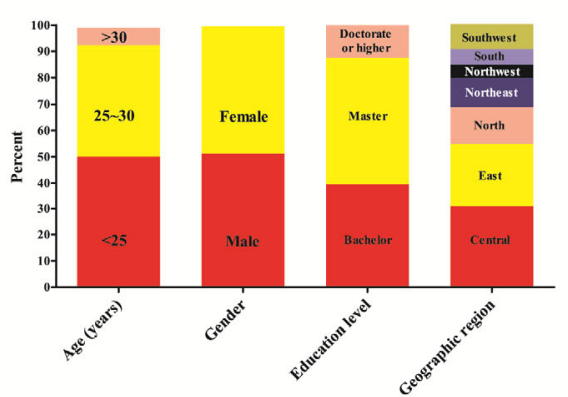

C

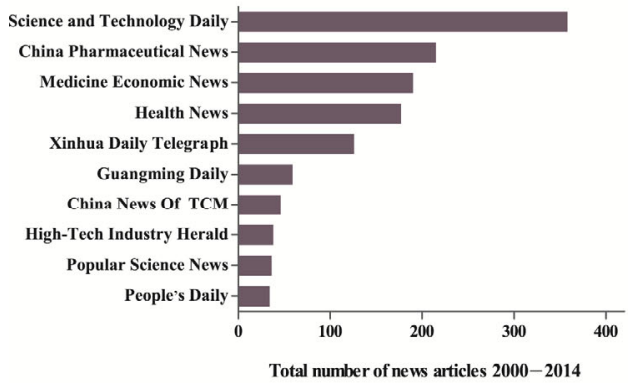

B

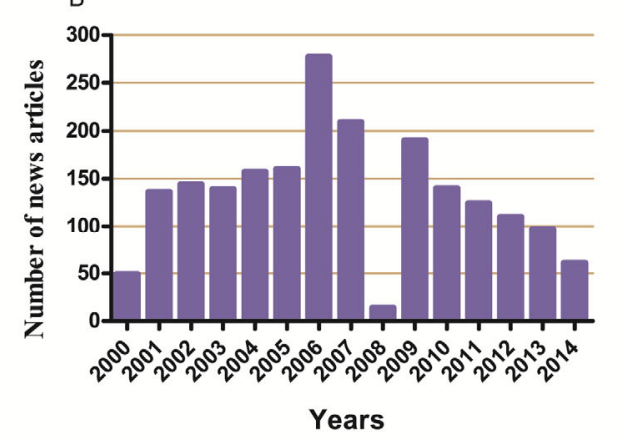

D

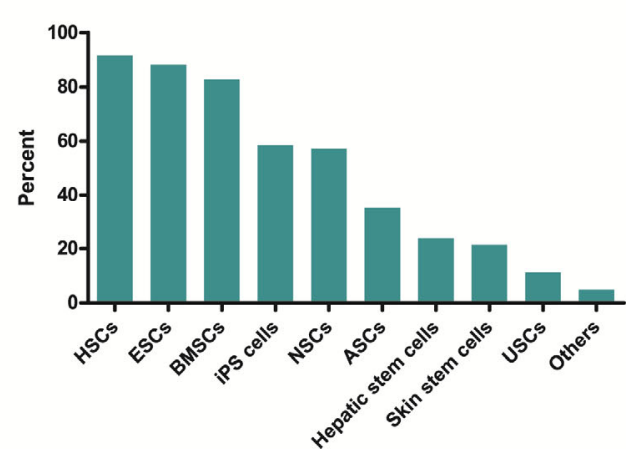

Figure 1 Results of a survey among health care workers and print news coverage of stem cells in Chinese newspapers. A, Characteristics of total participants. B, Trends in news articles published over the past 15 years (2000-2014). C, Top 10 contributors of news articles regarding stem cell research. D, Familiarity among the respondents with stem cells varied significantly by type. HSCs: hematopoietic stem cells; ESCs: embryonic stem cells; iPS cells: induced pluripotent stem cells; BMSCs: bone marrow-derived stem cells; ASCs: adipose-derived stem cells; NSCs: neural stem cells.

either somewhat or very familiar with more than three types of stem cells. Of the various types of stem cells, the participants seemed to be more familiar with hematopoietic stem cells, embryonic stem cells, and bone marrow-derived stem cells (Figure 1D). Further, just over half of participants were familiar with induced pluripotent stem cells and neural stem cells. The remaining respondents were familiar with adipose-derived stem cells (34.9\%), hepatic stem cells $(23.8 \%)$, skin stem cells $(21.4 \%)$, and urine-derived stem cells $(11.2 \%)$.

Although scientifically promising, the development of stem cell research has been hampered by fears regarding potential abuse of the stem cell technology (Cyranoski et al., 2012). Indeed, technical solutions may involve the use of human embryos, and this has created barriers to the use of the technology in many countries. Early embryos would be destroyed in the process of removing the stem cells, and some people consider it immoral to destroy an embryo for any purpose, including for medical research. Therefore, those who are more religious are more likely to support restrictions. However, patients or people with the least religious involvement are less likely to believe that embryonic stem cell research should be forbidden, as compared to their counterparts. They believe that the progressive development of appropriate legal and regulatory frameworks is needed to allow the scientific and clinical research to move forward.
For example, based on a large, representative sample survey conducted in 2008 , with 1,350 participants, $73 \%$ of the infertility patients felt that the use of leftover embryos for stem cell research should be allowed (Jain et al., 2008). In Nigeria, three-quarters of the surveyed dentists exhibited a positive attitude towards stem cell use (Sede et al., 2013). In addition, $80 \%$ of European citizens support embryonic stem cell research. Nearly $50.5 \%$ Germans supported use of embryonic stem cells for research. In the United States, $62 \%$ of the citizens surveyed believed that medical research using human embryonic stem cells is acceptable (O'Malley, J. 2014).

In China, our survey showed that $78.9 \%$ of the participants expressed high levels of interest in stem cells, especially those aged between 25 and 30 years, who were well educated. Respondents' interests were significantly associated with the participants' age, education level, and geographic region, but did not correlate with gender (Table S1). When asked if they agreed with the use of human embryos in stem cell research, roughly $63.5 \%$ said they definitely approved of it, $30.8 \%$ disapproved of it, and $5.7 \%$ had undecided or mixed feelings. The logistic regression showed that attitudes toward embryonic stem cell research correlated with the participants' gender, education level, and geographic region (Table S2). It means that the participants had mixed feelings about embryonic stem cell (ESC) research, 
with nearly equal number of participants supporting and opposing it. However, women were more likely than men to disapprove or strongly disapprove of ESC research. To our knowledge, this is the first study that examines the opinions of China's medical practitioners on the use of embryos for stem cell research, and to characterize their opinions according to their demographic and educational background.

It should be noted that induced pluripotent stem cells as modified adult cells might be an alternative. Significantly, public support was high, and supporters outnumbered opponents for treating human diseases. Similarly, our survey showed that more than three-quarters of the medical practitioners supported the development of induced pluripotent stem cells. Fewer than $4 \%$ of those questioned were against the use of these modified adult cells for medical research. These feelings correlated with the participants' age, education level, and geographic region, but not gender (Table S3).

Therefore, we conclude that Chinese health workers may like to be at the forefront of stem cell technology development, and are interested in the procedures that regenerate damaged tissue. We believe that these results will be used to help our scientists, partners, policymakers, physicians, and medical students improve the awareness and resources that they have identified as being important to them.

Compliance and ethics The author(s) declare that they have no conflict of interest.

Acknowledgements The author(s) are indebted to all colleagues and students who provided advice, assistance, and materials for this manuscript. This work was supported by the National Natural Science Foundation of China (30671538).

Cyranoski, D. (2012). China's stem-cell rules go unheeded. Nature 484, 149-150.

Jain, T., Missmer, S.A. (2008). Support for embryonic stem cell research among infertility patients. Fertil Steril 90, 506-512.

O'Malley, J. 2014-03-31. What does the public think about stem cell research? http://www.eurostemcell.org/faq/what-does-public-think- aboutstem-cell-research

Sede, M.A., Audu, O., Azodo, C.C. (2013). Stem cells in dentistry: knowledge and attitude of Nigerian dentists. BMC Oral Health 13, 27.

Yuan, W., Sipp, D., Wang, Z., Deng, H., Pei, D., Zhou, Q., Cheng, T.. (2012). Stem cell science on the rise in China. Cell Stem Cell 10, $12-15$.

Open Access This article is distributed under the terms of the Creative Commons Attribution License which permits any use, distribution, and reproduction in any medium, provided the original author(s) and source are credited.

\section{Supporting Information}

Table S1 Attitudes toward stem cell research

Table S2 Factors associated with ESC research by multivariate logistic regression analysis

Table S3 Factors associated with opinions regarding induced pluripotent stem cells

The supporting information is available online at life.scichina.com and link.springer.com. The supporting materials are published as submitted, without typesetting or editing. The responsibility for scientific accuracy and content remains entirely with the authors. 